\title{
Diabetes in pregnancy
}

\author{
Marina Scavini ${ }^{1} \cdot$ Antonio Secchi $^{2,3}$
}

Received: 27 April 2019 / Accepted: 6 May 2019 / Published online: 23 May 2019

(c) Springer-Verlag Italia S.r.l., part of Springer Nature 2019

The topic of diabetes in pregnancy encompasses the pregnancy of women with any form of diabetes (mainly type 1 or type 2 diabetes) diagnosed prior to conception (pregestational diabetes), as well as forms of diabetes and hyperglycemia diagnosed during pregnancy. Among the latter, the most frequent form is gestational diabetes, usually diagnosed during the second trimester of gestation, and less common are early pregnancy hyperglycemia due to undiagnosed pregestational type 2 or monogenic diabetes and early onset gestational diabetes. Exposure to hyperglycemia during pregnancy, regardless of the diagnosis, is a fast-growing challenge for women and their offspring, professionals and healthcare systems worldwide [1].

Although women with pregestational diabetes account only for 0.4 to $0.5 \%$ of all women delivering a baby, these pregnancies are at increased risk of unfavorable maternal and fetal/neonatal outcomes, including premature delivery, preeclampsia, large for gestational age newborns, cesarean sections, congenital malformations, neonatal hypoglycemia and stillbirths [2,3]. Unfortunately, over the past 30 years, there has been a limited improvement in pregnancy outcomes, even in countries with universal access to care [4]. In the last two decades, the number of pregnancies in women with type 2 diabetes has progressively increased up to $40-50 \%$ of the pregnancies complicated by pregestational diabetes [5], possibly because of the decreasing age of onset of the disease and increasing age at first pregnancy. Pregnancy outcomes in women with type 2 diabetes are similar or even worse than those of women with type

\section{Managed by Antonio Secchi.}

Marina Scavini

scavini.marina@hsr.it

1 Diabetes Research Institute, San Raffaele Scientific Institute, Milan, Italy

2 Vita-Salute San Raffaele University, Milan, Italy

3 Clinical Transplant Unit, Division of Immunology, Transplantation and Infectious Diseases San Raffaele Scientific Institute, Milan, Italy
1 diabetes, despite better glucose control since conception [6]. It is well established that pregnancy planning is key to minimize unfavorable pregnancy outcomes in women with pregestational diabetes. The aim of pregnancy planning is to achieve, prior to conception, optimal glucose control $(\mathrm{HbA} 1 \mathrm{c}<6.5 \%$ or $48 \mathrm{mmol} / \mathrm{mol}$, with low frequency of hypoglycemia), adequate supplementation of folic acid (4-5 mg/day), management of diabetes, diabetes complications and/or comorbidities that can be safely maintained throughout pregnancy, e.g., shifting women from oral agents to insulin and prescribing antihypertensives that can be used during pregnancy $[7,8]$. Unfortunately, a low proportion of women with pregestational diabetes takes advantage of pregnancy planning (less than 50\%), with the majority of pregnancies being unplanned [7, 8]. In real life the majority of women with diabetes have negative conditions for the start of a pregnancy [9]. Programs to promote pregnancy planning in women with pregestational diabetes have proven effective in increasing the rate of planned pregnancy and cost-effective in decreasing the costs of caring for high-risk pregnancies and offspring with perinatal morbidity or longterm disabilities [10,11].

Gestational diabetes (GDM) is one of the most common complications of pregnancy worldwide, with 5-20\% of newborns being offspring of mothers with diagnosed or undiagnosed GDM [12]. If not timely diagnosed and effectively treated, GDM is associated with an increased risk of adverse pregnancy outcomes for both the mother and the fetus/newborn, including preeclampsia, prematurity, cesarean section, macrosomia and neonatal hypoglycemia [13]. The wide range of GDM rates reported in different countries depends on the background susceptibility to type 2 diabetes, access to care, screening policies and degree of compliance to GDM screening by healthcare professionals caring for pregnant women and, not least, differences in diagnostic criteria [12]. The issue of which criteria to use for the diagnosis of GDM has created confusion for several decades, but has now been overcome by the pragmatic approach suggested by the FIGO [1], recognizing that any degree/form of hyperglycemia might have an impact on the newborn. 
In women with GDM, the exposure of the fetus to hyperglycemia starts usually beyond the ninth week of gestation (first trimester) when most of the organogenesis is completed; therefore, GDM should not affect the rate of congenital malformations. However, nowadays a large proportion of women with GDM is overweight or obese and obesity per se is associated with an increased rate of congenital malformations and acts in synergy with GDM to increase the risk of adverse pregnancy outcomes [14]. The impact of subtle alterations in glucose and other metabolites on fetal development is the field of active research.

Insulin is the only recommended treatment for hyperglycemia during pregnancy. Although there is insufficient evidence to recommend any oral medications $[15,16]$, many guidelines worldwide list metformin and/or glyburide as alternative options to insulin. Metformin for the treatment of GDM has been tested in RCTs with reassuring long-term follow-up of the offspring [17, 18]. On the other hand, there are still significant concerns about the use of glyburide to treat GDM, because of increased rate of unfavorable neonatal outcomes compared to metformin or insulin and lack of long-term data on the offspring [19].

Several approaches have been proposed to prevent GDM in women at increased risk, including lifestyle changes (diet and exercise), and use of supplements, either prior to pregnancy or during the first trimester of pregnancy [20-22]. However, at the moment no strong conclusions can be drawn with regard to the best intervention for preventing GDM.

The diagnosis of GDM also affects women well beyond pregnancy. Women with a pregnancy complicated with GDM have a sevenfold increased risk of developing type 2 diabetes in the years following childbirth and are more susceptible to cardiovascular events [23-25]. Unfortunately, the predictive value of GDM is unlikely recognized in practice, not prompting referral of these women to prevention programs aiming at decreasing the risk of both type 2 diabetes and CVD.

The purpose of this Topical Collection is to host original and review articles addressing the fast-growing challenges, research and understanding posed by the exposure to hyperglycemia during pregnancy. Professionals and healthcare systems worldwide need to increase their awareness about all different aspects of hyperglycemia and related metabolic abnormalities in pregnancy to shape the health of future generations. The goal to improve pregnancy outcomes in women with pregestational diabetes through careful pregnancy planning and in women with gestational diabetes through sustainable policies of screening and treatment should be in reach of most health care systems, being also widely supported by international health organizations. Furthermore, we should not miss the opportunity to put in place effective strategies to prevent diabetes and CVD in women with a history of GDM and to optimize health and growth of their children.

\section{Compliance with ethical standards}

Conflict of interest The authors declare they have no conflict of interest.

Ethical approval This article does not contain any studies with human participants performed by any of the authors.

\section{References}

1. Hod M, Kapur A, Sacks DA et al (2015) The International Federation of Gynecology and Obstetrics (FIGO) Initiative on gestational diabetes mellitus: a pragmatic guide for diagnosis, management, and care. Int J Gynaecol Obstet 131(Suppl 3):S173-S211. https://doi.org/10.1016/S0020-7292(15)30007-2

2. Confidential Enquiry into Maternal and Child Health. Pregnancy in women with type 1 and type 2 diabetes in 2002-2003. England, Wales, Northern Ireland. CEMACH, London, 2005. https://elear ning.rcog.org.uk//sites/default/files/Diabetes $\% 20$ and $\% 20$ other $\% 20$ endocrinopathies/CEMACH_Pregnancy_type_1_2_diabetes.pdf

3. Fadl HE, Simmons D (2016) Trends in diabetes in pregnancy in Sweden 1998-2012. BMJOpen Diabetes Res Care 4(1):e000221. https://doi.org/10.1136/bmjdrc-2016-000221

4. Mackin ST, Nelson SM, Kerssens JJ et al (2018) Diabetes and pregnancy: national trends over a 15 year period. Diabetologia 61(5):1081-1088. https://doi.org/10.1007/s00125-017-4529-3

5. National Pregnancy in Diabetes Audit Report (2016). http://diabe testimes.co.uk/wp-content/uploads/2017/10/National_Pregnancy_ in_Diabetes_2016_Report.pdf

6. Balsells M, García-Patterson A, Gich I, Corcoy R (2009) Maternal and fetal outcome in women with type 2 versus type 1 diabetes mellitus: a systematic review and metaanalysis. J Clin Endocrinol Metab 94(11):4284-4291. https://doi.org/10.1210/jc.2009-1231

7. American Diabetes Association (2019) Management of diabetes in pregnancy: standards of medical care in Diabetes 2019. Diabetes Care 42(Suppl. 1):S165-S172. https://doi.org/10.2337/dc19-S014

8. Diabetes in pregnancy overview. https://pathways.nice.org.uk/ pathways/diabetes-in-pregnancy

9. Scavini M, Rossi MC, Scardapane M et al (2018) Portrait of women with type 1 or type 2 diabetes of childbearing age attending diabetes clinics in Italy: the AMD-Annals initiative. Acta Diabetol 55(2):193-199. https://doi.org/10.1007/s00592-017-1076-9

10. Egan AM, Danyliv A, Carmody L, Kirwan B, Dunne FP (2016) A prepregnancy care program for women with diabetes: effective and cost saving. J Clin Endocrinol Metab 101(4):1807-1815. https ://doi.org/10.1210/jc.2015-4046

11. Yamamoto JM, Hughes DJF, Evans ML et al (2018) Community-based pre-pregnancy care programme improves pregnancy preparation in women with pregestational diabetes. Diabetologia 61(7):1528-1537. https://doi.org/10.1007/s00125-018-4613-3

12. Buckley BS, Harreiter J, Damm P et al (2012) Gestational diabetes mellitus in Europe: prevalence, current screening practice and barriers to screening. A review. Diabet Med 29(7):844-854. https ://doi.org/10.1111/j.1464-5491.2011.03541.x

13. HAPO Study Cooperative Research Group, Metzger BE, Lowe LP et al (2008) Hyperglycemia and adverse pregnancy outcomes. 
N Engl J Med 358(19):1991-2002. https://doi.org/10.1056/nejmo a0707943

14. Devlieger R, Benhalima K, Damm P et al (2016) Maternal obesity in Europe: where do we stand and how to move forward?: A scientific paper commissioned by the European Board and College of Obstetrics and Gynaecology (EBCOG). Eur J Obstet Gynecol Reprod Biol 201:203-208. https://doi.org/10.1016/j.ejogr b.2016.04.005

15. Langer $O$ (2018) Pharmacological treatment of gestational diabetes mellitus: point/counterpoint. Am J Obstet Gynecol 218(5):490-499. https://doi.org/10.1016/j.ajog.2018.01.024

16. Corcoy R, Balsells M, García-Patterson A, Shmueli A, Hadar E (2018) Pharmacotherapy for hyperglycemia in pregnancy-do oral agents have a place? Diabetes Res Clin Pract 145:51-58. https://doi.org/10.1016/j.diabres.2018.04.015

17. Rowan JA, Hague WM, Gao W, Battin MR, Moore MP; MiG Trial Investigators (2008) Metformin versus insulin for the treatment of gestational diabetes. N Engl J Med 358(19):2003-2015. https ://doi.org/10.1056/nejmoa0707193. Erratum in: N Engl J Med. 2008 Jul 3;359(1):106

18. Rowan JA, Rush EC, Plank LD et al (2018) Metformin in gestational diabetes: the offspring follow-up (MiG TOFU): body composition and metabolic outcomes at 7-9 years of age. BMJ Open Diabetes Res Care 6(1):e000456. https://doi.org/10.1136/bmjdr c-2017-000456

19. Balsells M, García-Patterson A, Solà I, Roqué M, Gich I, Corcoy R (2015) Glibenclamide, metformin, and insulin for the treatment of gestational diabetes: a systematic review and meta-analysis. BMJ 21(350):h102. https://doi.org/10.1136/bmj.h102

20. Davenport MH, Ruchat SM, Poitras VJ et al (2018) Prenatal exercise for the prevention of gestational diabetes mellitus and hypertensive disorders of pregnancy: a systematic review and meta-analysis. Br J Sports Med 52(21):1367-1375. https://doi. org/10.1136/bjsports-2018-099355

21. Donazar-Ezcurra M, López-Del Burgo C, Bes-Rastrollo M (2017) Primary prevention of gestational diabetes mellitus through nutritional factors: a systematic review. BMC Pregnancy Childbirth 17(1):30. https://doi.org/10.1186/s12884-016-1205-4

22. Vitagliano A, Saccone G, Cosmi E et al (2019) Inositol for the prevention of gestational diabetes: a systematic review and metaanalysis of randomized controlled trials. Arch Gynecol Obstet 299(1):55-68. https://doi.org/10.1007/s00404-018-5005-0

23. Kramer CK, Campbell S, Retnakaran R (2019) Gestational diabetes and the risk of cardiovascular disease in women: a systematic review and meta-analysis. Diabetologia. https://doi.org/10.1007/ s00125-019-4840-2

24. Huvinen E, Eriksson JG, Koivusalo SB et al (2018) Heterogeneity of gestational diabetes (GDM) and long-term risk of diabetes and metabolic syndrome: findings from the RADIEL study followup. Acta Diabetol 55(5):493-501. https://doi.org/10.1007/s0059 2-018-1118-y

25. McKenzie-Sampson S, Paradis G, Healy-Profitós J, St-Pierre F, Auger N (2018) Gestational diabetes and risk of cardiovascular disease up to 25 years after pregnancy: a retrospective cohort study. Acta Diabetol 55(4):315-322. https://doi.org/10.1007/ s00592-017-1099-2

Publisher's Note Springer Nature remains neutral with regard to jurisdictional claims in published maps and institutional affiliations. 